\title{
Malaria determining risk factors at the household level in two rural villages of mainland Equatorial Guinea
}

\author{
Mónica Guerra ${ }^{1}$, Bruno de Sousa ${ }^{2}$, Nicolas Ndong-Mabale ${ }^{3}$, Pedro Berzosa ${ }^{4}$ and Ana Paula Arez ${ }^{1 *}$ (i)
}

\begin{abstract}
Background: After the introduction of an artemisinin-based combination therapy, the reduction of prevalence of malaria infections has shown a remarkable progress during the last decade. However due to the lack of a consistent malaria control programme and socioeconomic inequalities, Plasmodium infection is still one of the major cause of disease in Equatorial Guinea, namely in the rural communities. This study explored the associated risk factors of malaria transmission at the microeconomic level (households) in two rural villages of mainland Equatorial Guinea.
\end{abstract}

Methods: This survey involved 232 individuals living in 69 households located in two rural villages, Ngonamanga and Miyobo, of coastal and interior of Equatorial Guinea, respectively. Malaria prevalence was measured by PCR and parasitaemia level by optical microscopy; household socioeconomic status (SES) was measured based on house characteristics using a 2-step cluster analysis. Logistic regression analysis was performed to investigate the relationship of a diverse set of independent variables on being diagnosed with malaria and on showing high levels of parasitaemia.

Results: The prevalence of Plasmodium spp. infection was $69 \%$, with $80 \%$ of households having at least one parasitaemic member. The majority of houses have eaves (80\%), walls of clay/wood (90\%) and zinc roof (99\%) and only $10 \%$ of them have basic sanitation facilities. The studied areas showed reduced rates of indoor residual spraying coverage (9\%), and long-lasting insecticide-treated net ownership (35\%), with none of these preventive tools showing any significant effects on malaria risk in these areas. Neither the risk of malaria infection (PCR positive result) or the development of high parasitaemia did show association with SES.

Conclusions: This study has contributed to reinforce the importance of living conditions associated to a high risk of malaria infection and vulnerability to develop high parasitaemia. This study also contributes to future malaria control interventions to be implemented in mainland Equatorial Guinea or in other countries with similar environmental conditions.

Keywords: Malaria infection, Plasmodium spp., Risk factors, Socioeconomic status, Equatorial Guinea

\footnotetext{
*Correspondence: aparez@ihmt.unl.pt

${ }^{1}$ Global Health and Tropical Medicine, GHTM, Instituto de Higiene e Medicina Tropical, IHMT, Universidade Nova de Lisboa, UNL, Rua da Junqueira 100, 1349-008 Lisbon, Portugal

Full list of author information is available at the end of the article
} 


\section{Background}

A significant decline in global malaria burden have been reported since 2000, mainly attributed to scale-up of interventions including indoor residual spraying (IRS), high coverage of long-lasting insecticide-treated net (LLIN), improvement of diagnostic testing and use of artemisinin-based combination therapy (ACT) [1]. However, globally, this parasitic disease persists as one of the deadliest in the world with 445,000 deaths estimated in 2016 and 216 million new cases, particularly in Africa, where $91 \%$ of the fatal cases occur [1].

Malaria burden depends on intrinsic (human, parasite, mosquito) and extrinsic (environmental, social, behavioural, political, economic conditions and disease-control efforts) factors, being the latter the most important and relevant one of the determinants for malaria control and prevention [2]. A recent published study, carried out in approximately the same region reported the influence of environmental factors, namely altitude and distance to rivers and forests, as risk factors of malaria infections, mainly associated to higher exposure to mosquito vector [3].

Associated risk factors of malaria at the microeconomic level were analysed in the context of a study which integrated analysis of malaria prevalence, molecular characterization of Plasmodium populations (anti-malarial resistance-associated mutations) and characterization of malaria risk determinants in two rural villages, Ngonamanga and Miyobo, of mainland Equatorial Guinea. Previous analysis hinted differences between the two villages, regarding frequency of anti-malarial resistance associated mutations and Plasmodium falciparum diversity associated to different socioeconomic characteristics, populations migration and different accessibilities to anti-malarial treatment [4]. In the present report, the association of socioeconomic status of families/households with local malaria burden was evaluated.

According to the Unicef Report on Regular Resources, Equatorial Guinea has the highest gross national income per capita in Africa, but its economy is very vulnerable to fluctuations in world oil prices and the evolution of hydrocarbon production and is marked by strong social inequalities [5]. Equatorial Guinea has a low population density, estimated at 62 inhabitants per $\mathrm{km}^{2}$, mostly concentrated in the cities of Bata, Malabo, Mbini Ebebiyin and Mongomo (Fig. 1). Significant pockets of poverty still exist in rural areas and according to the Second National Economic Conference in Equatorial Guinea conducted in 2007, 76.8\% of

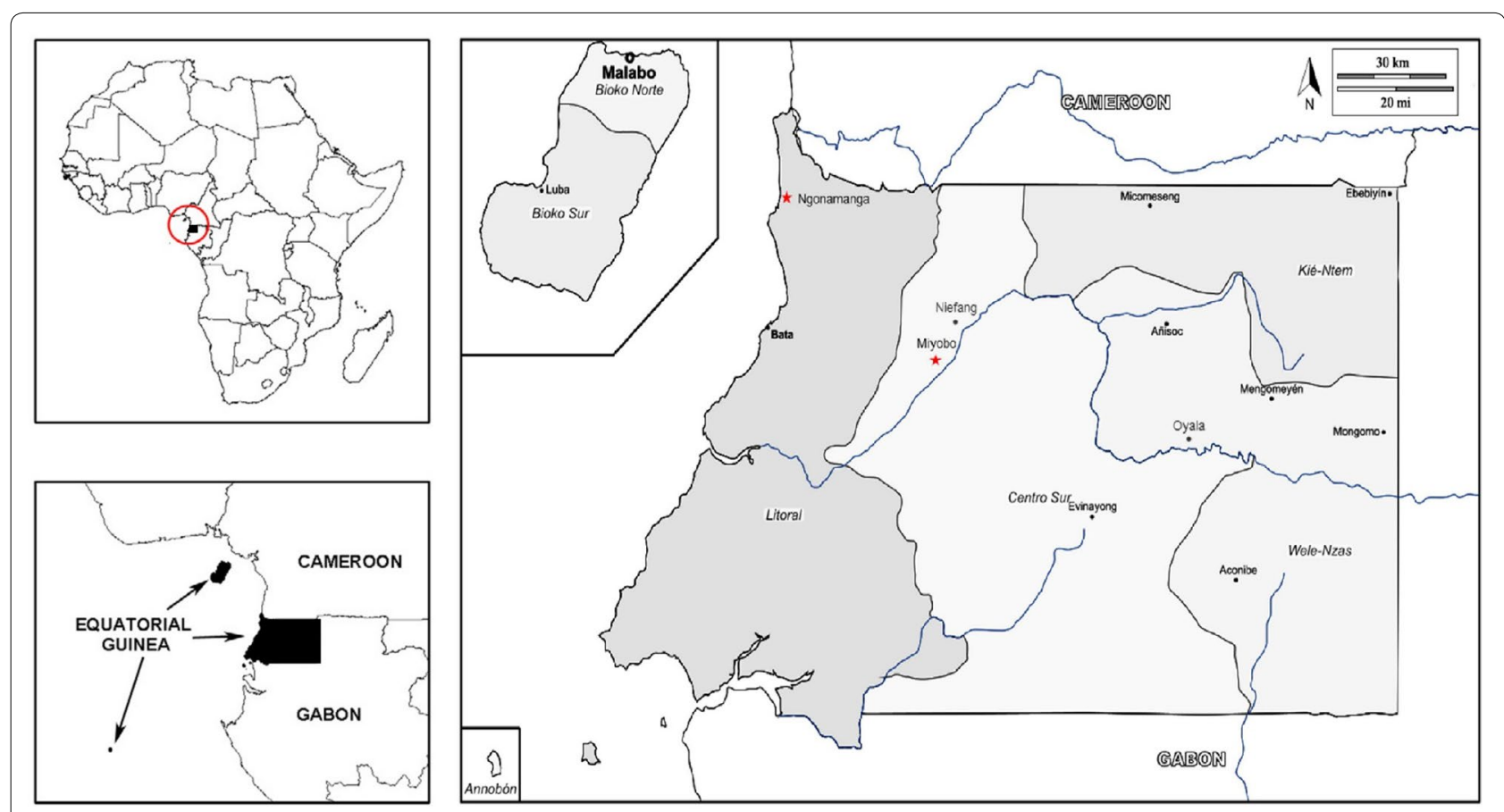

Fig. 1 Map of Equatorial Guinea with study areas. The country's capital is Malabo, on Bioko Island. Sampling took place in two villages of mainland Equatorial Guinea, Ngonamanga and Miyobo (red stars). Ngonamanga (Litoral province, N 02 $09^{\prime} 34,5^{\prime \prime} ; \mathrm{E} 009^{\circ} 47^{\prime} 54,4^{\prime \prime}$ ) is a coastland village, isolated from the main trade routes, having an older population, whereas Miyobo (Centro Sur province, N 01 ${ }^{\circ} 44^{\prime} 56,40^{\prime \prime} ; \mathrm{E} 10^{\circ} 10^{\prime} 40,05^{\prime \prime}$ ) is a village in the interior, but closer to a developing city Niefang and nearby a main road, having a younger population [4] 
the population lived below the poverty line, with a daily income less than \$2.00 USD [6].

In Equatorial Guinea, Plasmodium infections are among the leading causes of disease, with 1,221,495 of the population at risk for malaria infection, with over 291,700 cases estimated in 2016 (range 178,100419,000 ) and the cause of $15 \%$ of the mortality among children under 5 years [7].

In 2004, in order to meet the Millennium Development Goals set by the United Nations, government implemented control measures on Bioko Island under the Bioko Island Malaria Control Project (BIMCP), aiming at substantially reducing, and ultimately eliminating malaria from the island. Following the success achieved in 2007 on Bioko island [8], measures were introduced on the mainland through the Equatorial Guinea Malaria Control Initiative (EGMCI). This programme included vector control interventions (large scale distribution of LLIN in Centro Sur and Wele-Nzas provinces, and IRS in Litoral and Kie-Ntem provinces) (Fig. 1), effective case management and extensive education and communication outreach initiatives. Despite the initial success, the EGMCI's activities were discontinued in 2011 due to funding limitations and consequently, malaria prevalence remained high $[9,10]$.

Although Equatorial Guinea has been recently declared as a high income country (and, therefore, no longer eligible for funding from the Global Fund), it does not have an ongoing national malaria control programme, which poses a serious public health challenge for the mainland region and also is an obstacle to malaria elimination on Bioko Island, due to the increasing number of travellers from mainland [11].

\section{Methods}

\section{Study area}

Equatorial Guinea is a sub-Saharan country located in Central Africa. It consists of two regions, the mainland, called Rio Muni, bordered by Cameroon and Gabon and the island of Bioko (where the capital city of Malabo is located, Annobón, Corisco Bay, Elobey Chico and Elobey Grande). The mainland area of $26,000 \mathrm{~km}^{2}$ is divided in four provinces (Litoral, Centre Sur, Kié-Ntem and WeleNzas), with an estimated population of $1,835,270$ in 2014 [12].

The major ethnic groups in Equatorial Guinea are Bubi (15\%) in Bioko and Fang (80\%) in Rio Muni. The minorities (5\%) are Ndowes, Pygmies, Bisios, Fernandinos, Creoles and Annobonese [13]. In Rio Muni, the main language for inter-ethnic communication is Spanish (the official language), although Fang is highly used given the political and social hegemony of this group [14].
Although Equatorial Guinea has a tropical climate with two dry seasons in the continental region from December to mid-February and from July to September [15], malaria transmission is stable throughout the year [3]. Malaria is a major cause of morbidity and the fourth cause of death (5.7\%), following HIV/ AIDS (14.8\%), lower respiratory infections (10\%) and diarrheal diseases (8\%) [1]. In the continental region, malaria is holoendemic, with $P$. falciparum being the dominant species and Anopheles gambiae sensu lato (s.l.) being considered the primary vector for malaria transmission $[16,17]$.

The study took place in two rural mainland villages with high malaria transmission, Ngonamanga and Miyobo. Ngonamanga is a coastal village close to Equatorial Guinea-Cameroon border, with mainly Ndowe (Kombe) population and where fishing is the primary economic activity. Miyobo is a Fang village in the interior of the country, near to Niefang city (15 km apart), with farming as the main economic activity.

\section{Study design}

Between February and April 2013, a questionnaire was answered by all heads of households that agreed to voluntarily participate in the study, a total of 29 households in Ngonamanga and 40 in Miyobo to a total of 232 individuals (63 in Ngonamanga and 169 in Miyobo). According to the Centro de Referencia para el Control de Endemias, the estimated population density in October 2012 was 343 inhabitants in Miyobo and 69 in Ngonamanga. A malarial infection survey was done to all family members who agreed to participate. Two health technicians were selected from a list, together with the household to be visited in the following day. The health technicians informed the head of the household and family members and, in case of acceptance, a written consent was requested and the visit was scheduled for the next day. On the survey day, the individuals were fully identified, questionnaires answered and finger-prick blood samples collected. For each person, a rapid diagnostic test (RDT) $\left(\mathrm{NADAL}^{\circledR}\right.$ Malaria Test 4 species) was made, thick and thin blood films were performed, and some blood spotted onto Whatman ${ }^{\circledR} 903$ filter paper cards. According to the guidelines of the Ministry of Health, anti-malarial treatment of artesunate + amodiaquine $(\mathrm{AS}+\mathrm{AQ})$ with paracetamol was provided to patients with a positive RDT.

\section{Questionnaire}

The questionnaire was written in Spanish but, whenever needed, interviews were conducted in the local language, i.e. Fang. Information on demographics (e.g. gender, age, 
number of people living in the house), malaria prevention measures (e.g. windows protection, use of mosquito net the night before, IRS history), house construction conditions (e.g. type of wall, floor, roof, presence/absence of eaves), and socioeconomic indicators (e.g. water source for domestic use, lighting, cooking, toilet facility, owning domestic animals) were collected.

\section{Identification of Plasmodium species}

Giemsa-stained thick and thin blood films were examined under microscope at a $1000 \times$ magnification and parasite densities recorded as the number of parasites $/ \mu \mathrm{l}$ of blood, assuming an average leukocyte count of $8000 / \mu \mathrm{l}$ (all smears were examined against 500 leucocytes prior to be declared negative).

Plasmodium falciparum asexual parasitaemia was classified according to the following criteria: low ( $<800$ parasites $/ \mu \mathrm{l})$, moderate $(800-8000$ parasites $/ \mu \mathrm{l})$, and high $(\geq 8000$ parasites/ $\mu \mathrm{l})$ similarly to what have done in Guerra et al. [4].

Parasite genomic DNA was extracted from a blood spot on filter paper $(\sim 50 \mu \mathrm{l})$ using a standard phenolchloroform technique. Detection and identification of Plasmodium species were determined by nested-PCR amplification of the small subunit ribosomal RNA genes [18].

\section{Statistical analysis}

An initial descriptive statistical analysis was performed to the variables collected in the above questionnaire, followed by Chi squared tests and Fisher's Exact tests to determine possible associations between categorical variables. The variables used to estimate the socioeconomic status (SES) were based on the house characteristics, namely type of floor, walls, window protection, the presence of eaves, the energy source for cooking, toilet facilities, electricity, owning a bed net, and the number of people living in the house [19-22]. In order to establish the socioeconomic status of a household, a 2-step cluster analysis was the procedure used instead of a categorical Principal Component Analysis [23, 24], thus allowing for the inclusion of categorical and quantitative variables and the automatic selection of the number of clusters in the data.

Finally, two logistic regression analysis were performed at the individual and the household levels in order to investigate the relationship of a diverse set of independent variables on being diagnosed with malaria and on showing high levels of parasitaemia. Statistical analyses were performed using the IBM SPSS Statistics for Windows, version 22 [25], considering a significance level, $\alpha$, of 0.05 .

\section{Results}

\section{Household and individual characteristics}

All demographic, household and malaria variables in both villages, Miyobo and Ngonamanga are available in Additional file 1. In total, 69 households occupied by 232 individuals were surveyed (63 individuals in Ngonamanga and 169 in Miyobo). According to the Centro de Referencia para el Control de Endemias, the estimated population density in October 2012 was 69 in Ngonamanga and 343 inhabitants in Miyobo.

The participants' age ranged from 6 months to 99 years-old, with $16.4,19.4$ and $64.2 \%$ of the individuals belonging to the age groups 6 months to 5 years old, from 6 to 15 years of age and $>15$ years, respectively. Age distribution is different between villages $(P<0.001)$ due to an over-representation of older individuals ( $>15$ years) in Ngonamanga. The proportion of female participants were $52.6 \%$ with gender being independent of the participants' residence $(P=0.222)$ (Additional file 1$)$.

Demographic, household and malaria variables in Miyobo and Ngonamanga and their differences are presented in Additional file 1. In general, households are composed by an average number of $4.6(\mathrm{SD}=3.06)$ and $2.3(\mathrm{SD}=1.95)$ occupants in Miyobo and Ngonamanga, respectively, with $4.0(\mathrm{SD}=2.5)$ and $3.1(\mathrm{SD}=1.31)$ average number of rooms per household, respectively.

The majority of the houses have eaves (80\%), walls of clay/wood (90\%) and zinc roofs (99\%); floor type differs by village, with cement/tile present in 33 and $79 \%$ of the houses in Miyobo and Ngonamanga, respectively $(P=0.002)$. In total, $71 \%$ of the houses have access to electricity from an oil generator that is used only in special occasions, and some families owned electrical devices as a radio $(73 \%)$, television $(41 \%)$, refrigerator (13\%) or freezer $(32 \%)$. The source of water for domestic use is mainly provided by closed reservoirs (88\%). Firewood remains the most widely used source of power for cooking in Miyobo's families, while in Ngonamanga, 69\% of the families used gas or kerosene $(P<0.001)$. Only $2.5 \%$ of families had a flush toilet or a protected pit latrine in Miyobo, while in Ngonamanga $21 \%$ of families had better toilet facilities $(P=0.018)$.

Bed net ownership by household was $40 \%$ in Miyobo and $28 \%$ in Ngonamanga. Of those with access to a bed net, 36 and 19\% of individuals from Miyobo and Ngonamanga $(P=0.016)$, respectively, had slept under it the night before the interview. The use of bed nets is prioritized for the $0-5$ years old age group but it was higher in Ngonamanga (66\%, 2 out of 3 ) than in Miyobo (57\%, 20 out of 35). Usually one bed net was shared by two or three people (e.g., a couple and the youngest child). Less than $5 \%$ of the bed nets were treated with insecticide in both villages. 
Table 1 Occurrence, indicated as a percentage, of each predictor variable as determined in the 2-step cluster analysis

\begin{tabular}{|c|c|c|c|c|c|c|}
\hline & Socioeconor & & & & & \\
\hline & More poor & $\%$ & Poor & $\%$ & Less poor & $\%$ \\
\hline Households & 27 & 39.1 & 22 & 31.9 & 20 & 29.0 \\
\hline Average household size & 2.78 & & 5.64 & & 2.65 & \\
\hline Eaves present & & 92.6 & & 81.8 & & 60 \\
\hline Source of water for domestic use & Low quality & 88.9 & Low quality & 90.9 & Low quality & 90.0 \\
\hline Toilet facility & High quality & 100 & High quality & 100 & High quality & 65.0 \\
\hline Has at least 1 electric appliance & & 70.4 & & 100 & & 100 \\
\hline Source of power for cooking & Low quality & 92.6 & Low quality & 100 & High quality & 100 \\
\hline Wall type & Low quality & 100 & Low quality & 54.5 & Low quality & 65.0 \\
\hline Floor type & Low quality & 81.5 & High quality & 77.3 & High quality & 100 \\
\hline Roof type & High quality & 100 & High quality & 100 & High quality & 95.0 \\
\hline Windows protection & Low quality & 74.1 & High quality & 81.8 & High quality & 70.0 \\
\hline Bed net ownership & Low quality & 85.2 & High quality & 68.2 & Low quality & 75.0 \\
\hline
\end{tabular}

\section{Socioeconomic status (SES)}

The results from a 2-step cluster analysis based on the house characteristics determined three levels for the SES, "Less poor", "Poor", and "More Poor", with $29.0 \%(\mathrm{n}=20)$, $31.9 \%(\mathrm{n}=22)$ and $39.1 \%(\mathrm{n}=27)$ belonging to these categories, respectively (Table 1 ). All members of one household were classified according the SES classification of the house determined by this analysis.

\section{Malaria infection rates}

The prevalence of Plasmodium spp. infection was already reported in Guerra et al. [4]. The value estimated by nested-PCR was $71.4 \%$ in Ngonamanga and $68.0 \%$ in Miyobo, higher than the one estimated by optical microscopy (OM), 45.6 and $55.6 \%$, respectively, or by RDT, 49.1 and $55.6 \%$. Three Plasmodium species-P. falciparum, Plasmodium malariae and Plasmodium ovale were identified, with $P$. falciparum the predominant species occurring in $98 \%$ of the isolates from Ngonamanga and $96 \%$ from Miyobo, with 21\% of mixed infections [4].

Ninety-three percent of the 158 samples tested positive for malaria by OM showed low parasitaemia $(89 \%$ in Ngonamanga; 95\% in Miyobo); 50 samples were found positive by PCR and negative by OM (13 in Ngonamanga and 37 in Miyobo) and 55 PCR-positive and RDT-negative (17 in Ngonamanga and 38 in Miyobo) were also assigned to the low parasitaemia group of $<800$ parasites/ $\mu \mathrm{l}$. In the present study, OM revealed slightly better performance than NADAL ${ }^{\circledR}$ Malaria Test 4 species as shown in Table 2 and both lose sensitivity with age (Additional file 2). When detecting P. falciparum in single or mixed infection as compared to PCR, OM had a sensitivity of $68.8 \%$ (95\% CI $60.5-75.5)$, and specificity of $94.4 \%$ (95\% CI 86.4-98.5) while the NADAL ${ }^{\circledR}$ Malaria Test 4 species had a sensitivity of $65.6 \%$ (95\% CI $57.7-72.9)$, and

Table 2 Sensitivity, specificity, predicative values of optical microscopy (OM) and NADAL ${ }^{\circledR}$ Malaria Test 4 species with PCR as gold standard

\begin{tabular}{|c|c|c|c|c|c|c|}
\hline & $\begin{array}{l}\text { Positive PCR } \\
(n=160)\end{array}$ & Negative PCR $(n=72)$ & Sensitivity \% $\left(\mathrm{Cl}_{95}\right)$ & Specificity \% $\left(\mathrm{Cl}_{95}\right)$ & PPV \% $\left(\mathrm{Cl}_{95}\right)$ & $\mathrm{NPV} \%\left(\mathrm{Cl}_{95}\right)$ \\
\hline \multicolumn{7}{|l|}{ Microscopy } \\
\hline Positive $(n=112)$ & 108 & 4 & $68.8(60.5-75.5)$ & $94.4(86.4-98.5)$ & $96.4(91.2-98.6)$ & $57.6(51.8-63.3)$ \\
\hline Negative $(n=118)$ & 50 & 68 & & & & \\
\hline Missing $(n=2)$ & 2 & & & & & \\
\hline \multicolumn{7}{|l|}{ NADAL test } \\
\hline Positive $(n=112)$ & 105 & 7 & $65.6(57.7-72.9)$ & $90.3(81.0-96.0)$ & $93.8(88.0-96.8)$ & $54.2(48.5-59.7)$ \\
\hline \multirow[t]{2}{*}{ Negative $(n=120)$} & 55 & 65 & & & & \\
\hline & & P-value $=0.212^{*}$ & & & & \\
\hline
\end{tabular}

PVP positive predictive value, NVP negative predictive value, $\mathrm{Cl}_{95} 95 \%$ confidence interval

* DeLong's test for two correlated ROC curves with $\mathrm{AUC}_{\text {microscopy }}=81.6 \%$ and AUCNADAL test $=80.0 \%$ 
specificity of $90.3 \%$ (95\% CI 81.0-96.0). Nevertheless, these differences were not statistically significant $(\mathrm{P}=0.212)$.

\section{Malaria determinants and parasitaemia levels}

There was an association between the individual SES and the villages where they live $(P<0.001)$, with Ngonamanga showing lower levels of SES, i.e. the rejection of independence is due to a lower number of individuals classified as "Poor" together with an excess of them in the level "More Poor" in Ngonamanga. No significant association was found between SES and the presence of malaria infection (PCR diagnosis, $P=0.512$ ), nor SES and parasitaemia level $(P=0.732$, Fisher's Exact test).

High levels of parasitaemia showed significant association with age $(P=0.007$, Fisher's Exact test) with an excess of higher parasitaemia cases in the $0-5$ years old age group, and with the presence of animals around the house $(P=0.003$, Fisher's Exact test) with higher parasitaemia in individuals living with no animals.

Logistic regression analysis, controlled by age, between determinants (IRS, use of bed net and presence of animals) and PCR positive result and high parasitaemia as dependent variables (DV) at individual level is shown in Table 3. Considering a positive PCR result as DV, with the exception of age that showed a lower risk of infection for older people $[\mathrm{OR}=0.979,95 \% \mathrm{CI}=(0.967-0.991)]$, none of the independent variables were found to be statistically significant, but IRS and the use of a bed net seemed to indicate a decrease in the risk of the infection. When high levels of parasitaemia was considered as DV, only the presence of animals in the vicinity of the house and age showed to be a statistically significant protective factor against high parasitaemia $[\mathrm{OR}=0.053,95 \%$
$\mathrm{CI}=(0.010-0.288) ; \mathrm{OR}=0.947,95 \% \mathrm{CI}=(0.907-0.989)$, respectively].

In Table 4, a logistic regression analysis was carried out at the household level, i.e., the value of 1 was assumed if at least one member of the household had a PCR positive or high parasitaemia levels. The household size appeared as a significant factor in both models, indicating that a larger household is associated with an increased risk of infection $[\mathrm{OR}=4.771,95 \% \mathrm{CI}=(1.408-16.168)]$ and for high parasitaemia $[\mathrm{OR}=1.475,95 \% \mathrm{CI}=(1.024-2.123)]$. Once again, the presence of animals in the vicinity of the house seems to be a protective factor against high parasitaemia $[\mathrm{OR}=0.070,95 \% \mathrm{CI}=(0.007-0.680)]$.

\section{Discussion}

This study was carried out in two villages, Ngonamanga and Miyobo, of mainland Equatorial Guinea considered a high and stable malaria transmission setting [10]. Malaria prevalence and molecular characterization of Plasmodium populations (anti-malarial resistance-associated mutations) were previously reported [4] and allowed the analysis of results before and after the introduction of an artemisinin-based combination therapy (ACT), i.e., artesunate plus amodiaquine, 8 years apart [26]. Then, an overall prevalence of Plasmodium spp. infection of 69\% was determined, $17 \%$ in children under 5 year-old. From the 69 studied households, $80 \%$ have at least one infected individual and the majority of cases were asymptomatic. The prevalence of malaria infections decreased by $18 \%$, when compared to data reported by Mendes et al. [26] in the same areas, probably due to the malaria therapeutic change to AS + AQ in 2009. Although showing remarkable progress, malaria still is very prevalent, namely in such rural communities [17]. The present report intends

Table 3 Determinants for PCR positive result and high parasitaemia in logistic regression analysis at individual level

\begin{tabular}{|c|c|c|c|c|c|c|}
\hline \multirow[t]{2}{*}{ Response variable } & \multicolumn{3}{|c|}{ PCR positive result } & \multicolumn{3}{|c|}{ High parasitaemia } \\
\hline & OR & $95 \% \mathrm{Cl}$ & P-value & OR & $95 \% \mathrm{Cl}$ & P-value \\
\hline Age & 0.979 & $0.967-0.991$ & 0.001 & 0.947 & $0.907-0.989$ & 0.014 \\
\hline \multicolumn{7}{|l|}{$\operatorname{IRS}^{\mathrm{a}}$} \\
\hline No & 1 & & & 1 & & \\
\hline Yes & 0.854 & $0.398-1.831$ & 0.685 & 5.683 & $0.953-33.885$ & 0.056 \\
\hline \multicolumn{7}{|l|}{ Bed net $^{b}$} \\
\hline No & 1 & & & 1 & & \\
\hline Yes & 0.794 & $0.411-1.531$ & 0.490 & 0.898 & $0.902-4.397$ & 0.898 \\
\hline \multicolumn{7}{|l|}{ Animalsc } \\
\hline No & 1 & & & 1 & & \\
\hline Yes & 1.150 & $0.534-2.477$ & 0.721 & 0.053 & $0.010-0.288$ & 0.001 \\
\hline
\end{tabular}

Italic values indicate significance of $P$ value $(P<0.05)$

a Indoor residual spraying

b People sleeping under a bed net the night before

c Animals in the vicinity of the house 
Table 4 Determinants for PCR positive result in logistic regression analysis at household level (at least one member of the household was PCR-positive) and high parasitaemia level

\begin{tabular}{|c|c|c|c|c|c|c|}
\hline \multirow[t]{2}{*}{ Response variable } & \multicolumn{3}{|c|}{ PCR positive result } & \multicolumn{3}{|c|}{ High parasitaemia } \\
\hline & OR & $95 \% \mathrm{Cl}$ & P-value & OR & $95 \% \mathrm{Cl}$ & P-value \\
\hline \multicolumn{7}{|l|}{$\mathrm{IRS}^{\mathrm{a}}$} \\
\hline No & - & - & - & 1 & & \\
\hline Yes & - & - & - & 5.071 & $0.733-35.053$ & 0.100 \\
\hline \multicolumn{7}{|l|}{ At least Bed net used ${ }^{b}$} \\
\hline No & 1 & & & 1 & & \\
\hline Yes & 0.776 & $0.126-4.773$ & 0.785 & 0.860 & $0.147-5.046$ & 0.868 \\
\hline \multicolumn{7}{|l|}{ Animals ${ }^{c}$} \\
\hline No & 1 & & & 1 & & \\
\hline Yes & 3.522 & $0.787-15.756$ & 0.100 & 0.070 & $0.007-0.680$ & 0.022 \\
\hline Household size & 4.771 & $1.408-16.168$ & 0.012 & 1.475 & $1.024-2.123$ & 0.037 \\
\hline
\end{tabular}

Italic values indicate significance of $P$ value $(P<0.05)$

a Indoor residual spraying

b People sleeping under a bed net the night before

c Animals in the vicinity of the house

to analyse and characterize the main malaria risk determinants in the two villages.

On a macro-scale, malaria is frequently referred as a disease of poverty. However, on a micro-scale the evidence is less consistent and more difficult to analyse and understand [27]. The present study reinforces the importance of both individual and household level factors in determining not only the risk of infection but also the risk of developing high parasitaemia in a region and a country still exposed to a very high level of malaria infection.

Equatorial Guinea still is one of the countries more affected by malaria [28]. Following the success of the BIMCP [11], malaria control has been extended to mainland Equatorial Guinea under the EGMCI but despite the moderate positive impact on the malaria infection rate, malaria control interventions on mainland are few or non-existent since 2011 [10]. According to data published by Unicef and the World Health Organization [29], 71\% of rural Equatorial Guinea population uses an improved sanitation facility, and $31 \%$ uses an improved drinking water source. In this study, in both villages, more houses with access to some improved source of water for domestic use $(88 \%)$ were found but there is no information about how safe this water was for consumption, and only $10 \%$ have basic sanitation facilities, a lower number than reported. Additionally, the majority of walls, floors, roofs, and windows were built with low quality housing materials, with both villages showing a low SES since people live in poor conditions.

Results failed to point an effect of SES either on the risk of malaria infection or on the risk of developing high parasitaemia. An high SES has been associated with a reduction in malaria infection risk [22, 27, 30], mainly due to the improvement of housing conditions, possibly with less mosquitoes inside the house, but Worrall et al. [27] reported that most studies that use material assets as a proxy for SES have failed to establish a positive relationship between asset ownership and a reduced incidence of malaria episodes at the household level. This lack of consistent socioeconomic differentials in malaria prevalence is not necessarily counterintuitive given the epidemiology of malaria transmission. On the contrary, the evidence of vulnerability of low SES groups is consistent and associated to inequities in access to prevention and treatment.

At both household and individual level, the household size was naturally associated to an increased malaria infection risk and vulnerability to develop high parasitaemia, corroborating what is reported in other studies that suggest that mosquitoes are more attracted to large households due to the high concentration of mosquito-attracting human emanations (carbon dioxide) $[22,31]$. The studied areas showed reduced rates of IRS coverage (9\%) and LLIN ownership (35\%), and none of these preventive tools showed any significant effect on malaria risk. LLINs are infrequently used and those in use showed poor quality. During interviews, it was noticed that in some households bed nets were not hung onto a bed because people did not know how to use them; in others, bed nets were found in bad condition with visible holes.

Also to be noted from the results is that, despite their low application, most of the prevention measures were indoor whereas the probability of mosquito biting is 
mainly outdoor, thus those measures may not be very effective. As an example, this is shown by the fact that multivariate analysis at both individual and household levels suggested that the presence of animals around the house reduced the odds for a high parasitaemia. Animals may draw mosquitoes away from humans, reducing their exposure to malaria and protecting against high parasitaemia due to superinfection; alternatively, their presence may improve availability of blood meals, increasing vector density and longevity [32-34].

Entomological studies in the region suggest that An. gambiae s.l., Anopheles funestus, Anopheles moucheti and Anopheles nili s.l. are vectors of malaria in Rio Muni with An. gambiae sensu stricto (s.s.) being the major vector [35]. Although An. gambiae s.s. is usually defined as an endophagic and endophilic mosquito, exophagy and opportunistic feeding on animals have been observed in An. gambiae s.s. when human hosts are less available [36, 37]. Reddy et al. [38] have recently reported that malaria vectors on Bioko Island experienced a shift in host-seeking behaviour and approximately $40 \%$ of An. gambiae s.l. showed exophagic tendencies. Further entomological evaluation of local vector populations is required to clarify this effect.

The education level, a key factor for a sustainable response against malaria [39], has not been evaluated in this study. The knowledge about malaria transmission and prevention is crucial to improve living conditions and house construction in rural areas, which has an impact in endemic vector borne diseases. Recent Equatorial Guinea statistical information shows that in 2012, net enrolment in primary education was only $61 \%$, and probably this number is lower in rural populations [40]. Romay-Barja et al. [41] studied individual knowledge about malaria in Bata district (urban and rural areas) and reported that almost $65 \%$ of the individuals living in the rural areas were unaware of how malaria is transmitted and the use of bed nets were mentioned more to prevent mosquito nuisance than for malaria prevention and this lack of information about malaria prevention tools and practices was frequent in both villages.

Though the discovery of oil creates an opportunity to enhance the country infrastructure and to improve the general well-being of citizens, the oil reserves are currently on the brink of being exhausted. As a part of the Horizon 2020, the Government adopted the National Plan for Economic and Social Development, which targets economic diversification and poverty reduction. The first phase, focused on infrastructure development, was concluded in 2012. The second phase will focus on economic diversification and ensure sustainability of the country economy, targeting strategic new sectors such as fisheries, agriculture, tourism, and finance [40, 42].

With the economy instability, countries tend to abandon malaria control programmes, a fact that occurred in Equatorial Guinea since 2011. After the success observed with BIMCP, to know the environmental conditions of the villages is of the utmost importance in order to design and implement effective measurements in accordance with the economic inequalities present in the continental area.

\section{Conclusion}

This study has contributed to reinforce the importance of living conditions associated to a high risk of malaria infection and vulnerability to develop high parasitaemia. This study also contributes to future malaria control interventions to be implemented in mainland Equatorial Guinea or in other countries with similar environmental conditions.

\section{Additional files}

Additional file 1. Demographic, household and malaria variables in Miyobo and Ngonamanga.

Additional file 2. Sensitivity, specificity and predictive values of optical microscopy (OM) and NADAL ${ }^{\circledR}$ Malaria Test 4 species by age group with PCR as gold standard.

\section{Abbreviations \\ ACT: artemisinin-based combination therapy; AQ: amodiaquine; AS: artesu- nate; BIMCP: Bioko Island Malaria Control Project; Cl: confidence interval; DV: dependent variable; EGMCI: Equatorial Guinea Malaria Control Initiative; IRS: indoor residual spraying; LLIN: long-lasting insecticide-treated net; OM: optical microscopy; OR: odds ratio; P: P-value; PCR: polymerase chain reaction; RDT: rapid diagnostic test; SD: standard deviation; SES: socioeconomic status.}

\section{Authors' contributions}

Conceived and designed the experiments: APA, PB. Performed the experiments: MG, NN-M. Analysed the data: MG, BdS, APA. Contributed reagents/ materials/analysis tools: APA, PB. Wrote the paper: MG, BdS, APA. All authors revised the manuscript critically for important intellectual content. All authors read and approved the final manuscript.

\section{Author details \\ ${ }^{1}$ Global Health and Tropical Medicine, GHTM, Instituto de Higiene e Medicina Tropical, IHMT, Universidade Nova de Lisboa, UNL, Rua da Junqueira 100, 1349-008 Lisbon, Portugal. ${ }^{2}$ Faculdade de Psicologia e de Ciências da Educação, CINEICC, Universidade de Coimbra, Coimbra, Portugal. ${ }^{3}$ Centro de Referencia para el Control de Endemias, Instituto de Salud Carlos III, Bata, Equatorial Guinea. ${ }^{4}$ Centro Nacional de Medicina Tropical, Instituto de Salud Carlos III, Madrid, Spain.}

\section{Acknowledgements}

We thank all families who participated in this study. We thank the researchers and technicians from the National Malaria Control Programme of Equatorial Guinea's Ministry of Health and Social Welfare and the Centro de Referencia para el Control de Endemias (Instituto de Salud Carlos III, Equatorial Guinea).

\section{Competing interests}

The authors declare that they have no competing interests. 


\section{Availability of data and materials}

The datasets used for analysis of the study are available from the corresponding author upon receipt of reasonable request.

\section{Consent for publication \\ Not applicable.}

\section{Ethics approval and consent to participate}

Each person (or parent) who participated in this study was informed of its nature and aims, told that participation was voluntary, and given the option to withdraw at any time. Blood samples were collected after written informed consent from all donors (parents or guardians responded on behalf of children). A code number was assigned to each participant who answered a questionnaire, and confidentiality was guaranteed regarding all information obtained. The study was approved by the local health authorities from these villages, the Ethical Committee of the Equatorial Guinea's Ministry of Health and Social Welfare and the National Malaria Control. Ethical clearance was also given by the Ethical Committees of IHMT and the ISCIII, according to EU norms.

\section{Funding}

This study was supported by Grants PEst-OE/SAU/LA0018/2011-Proj. Estratégico LA0018 2011/2012, PTDC/SAU-EPI/113326/2009, and GHTM-UID/ Multi/04413/2013, from the Fundação para a Ciência e Tecnologia/Ministério da Educação e Ciência (FCT), Portugal, and the Instituto de Salud Carlos III, Ministerio de Ciencia e Innovación, Madrid, Spain.

\section{Publisher's Note}

Springer Nature remains neutral with regard to jurisdictional claims in published maps and institutional affiliations.

Received: 15 December 2017 Accepted: 9 May 2018

Published online: 18 May 2018

\section{References}

1. WHO. World malaria report 2017. Geneva: World Health Organization; 2017.

2. Breman JG. The ears of the hippopotamus: manifestations, determinants, and estimates of the malaria burden. Am J Trop Med Hyg. 2001;64(1-2 Suppl):1-11.

3. Gómez-Barroso D, García-Carrasco E, Herrador Z, Ncogo P, Romay-Barja M, Mangue MEO, et al. Spatial clustering and risk factors of malaria infections in Bata district, Equatorial Guinea. Malar J. 2017;16:146.

4. Guerra M, Neres R, Salqueiro P, Mendes C, Ndong-Mabale N, Berzosa P, et al. Plasmodium falciparum genetic diversity in continental Equatorial Guinea before and after introduction of artemisinin-based combination therapy. Antimicrob Agents Chemother. 2017;61:e02556-3015.

5. Unicef. Report on Regular Resources 2016. https://www.unicef.org/publi cations/files/Report_on_Regular_Resources_2016.pdf. Accessed 10 Apr 2018.

6. Puthod D, Pla L, Gallardo G. Perspectives économiques en Afrique-Guinée Équatoriale 2015. In: African Economic Outlook. 2017. http://www. africaneconomicoutlook.org/en/country-notes/central-africa/equatorial -guinea/. Accessed 3 Apr 2018.

7. WHO. Equatorial Guinea: WHO statistical profile. Geneva: World Health Organization; 2015. http://www.who.int/gho/countries/gnq.pdf?ua=1. Accessed 3 Jan 2016

8. Kleinschmidt I, Schwabe C, Benavente L, Torrez M, Ridl FC, Segura JL, et al. Marked increase in child survival after four years of intensive malaria control. Am J Trop Med Hyg. 2009;80:882-8.

9. Charle P, Berzosa P, Descalzo MA, de Lucio A, Raso J, Obono J, et al. Efficacy of artesunate + sulphadoxine-pyrimethamine (as $+\mathrm{sp}$ ) and amodiaquine + sulphadoxine-pyrimethamine $(a q+s p)$ for uncomplicated falciparum malaria in Equatorial Guinea (Central Africa). J Trop Med. 2009;2009:781865.

10. Rehman AM, Mann AG, Schwabe C, Reddy MR, Roncon Gomes I, Slotman $M A$, et al. Five years of malaria control in the continental region, Equatorial Guinea. Malar J. 2013;12:154
11. Bradley J, Monti F, Rehman AM, Schwabe C, Vargas D, Garcia G, et al. Infection importation: a key challenge to malaria elimination on Bioko Island, Equatorial Guinea. Malar J. 2015;14:46.

12. African Economic Outlook. Country notes_Equatorial Guinea. 2015. http://www.africaneconomicoutlook.org/sites/default/files/2016-05/ EQUATORIAL\%20GUINEA.pdf. Accessed 4 Jan 2017.

13. Official Web Page of the Government of the Republic of Equatorial Guinea. Ethnic groups, cultures and languages. 2015. http://www.guine aecuatorialpress.com/noticia.php?id=134\&lang=en. Accessed 29 Oct 2015.

14. Lipski J. The Spanish of Equatorial Guinea: research on la hispanidad's best-kept secret on JSTOR. Afro-Hispanic Rev. 2000;19:11-38.

15. Equatorial Guinea. The climate and relief. Official Web Page of the Government of the Republic of Equatorial Guinea. 2015. http://www.guine aecuatorialpress.com/noticia.php?id=133\&lang=es. Accessed 29 Oct 2015.

16. Cano J, Descalzo MA, Moreno M, Chen Z, Nzambo S, Bobuakasi L, et al. Spatial variability in the density, distribution and vectorial capacity of anopheline species in a high transmission village (Equatorial Guinea). Malar J. 2006:5:21.

17. Ncogo P, Herrador Z, Romay-Barja M, García-Carrasco E, Nseng G, Berzosa $P$, et al. Malaria prevalence in Bata district, Equatorial Guinea: a crosssectional study. Malar J. 2015;14:456.

18. Snounou G, Viriyakosol S, Jarra W, Pinheiro L, do Rosario VE, Thaithong $\mathrm{S}$, et al. High sensitivity of detection of human malaria parasites by the use of nested polymerase chain reaction. Mol Biochem Parasitol. 1993;61:315-20.

19. Filmer D, Pritchett LH. Estimating wealth effects without expenditure data-or tears: an application to educational enrollments in states of India. Demography. 2001;38:115-32.

20. Vyas S, Kumaranayake L. Constructing socio-economic status indices: how to use principal components analysis. Health Policy Plan. 2006;21:459-68.

21. Sonko ST, Jaiteh M, Jafali J, Jarju LBS, D’Alessandro U, Camara A, et al. Does socio-economic status explain the differentials in malaria parasite prevalence? Evidence from The Gambia. Malar J. 2014;13:449.

22. Kateera F, Mens PF, Hakizimana E, Ingabire CM, Muragijemariya L, Karinda $P$, et al. Malaria parasite carriage and risk determinants in a rural population: a malariometric survey in Rwanda. Malar J. 2015;14:16.

23. Chiu T, Fang D, Chen J, Wang Y, Jeris $C$. A robust and scalable clustering algorithm for mixed type attributes in large database environment. In: Proceedings of the seventh ACM SIGKDD international conference on knowledge discovery and data mining. ACM: San Francisco; 2001.

24. Ebeling B, Vargas C, Hubo S. Combined cluster analysis and principal component analysis to reduce data complexity for exhaust air purification. Open Food Sci J. 2013;7:8-22.

25. IBM Corp. Released 2013. IBM SPSS statistics for windows, version 22.0. Armonk: IBM Corp.

26. Mendes C, Salgueiro P, Gonzalez V, Berzosa P, Benito A, do Rosário VE, et al. Genetic diversity and signatures of selection of drug resistance in Plasmodium populations from both human and mosquito hosts in continental Equatorial Guinea. Malar J. 2013;12:114.

27. Worrall E, Basu S, Hanson K. The relationship between socio-economic status and malaria: a review of the literature. For ensuring that malaria control interventions reach the poor, London 5th-6th September 2002. http://siteresources.worldbank.org/INTMALARIA/Resources/SESMalaria BackgroundPaper.pdf. Accessed 20 May 2016.

28. Noor AM, Kinyoki DK, Mundia CW, Kabaria CW, Mutua JW, Alegana VA et al. The changing risk of Plasmodium falciparum malaria infection in Africa: 2000-2010: a spatial and temporal analysis of transmission intensity. Lancet. 2014;383:1739-47.

29. Unicef and WHO. Progress on sanitation and drinking water-2015 update and MDG assessment. Geneva: World Health Organization; 2015. http://www.who.int/about/licensing/copyright_form/en/index.html. Accessed 24 June 2016.

30. Ayele DG, Zewotir TT, Mwambi HG. Prevalence and risk factors of malaria in Ethiopia. Malar J. 2012;11:195.

31. Lwetoijera DW, Kiware SS, Mageni ZD, Dongus S, Harris C, Devine GJ, et al. A need for better housing to further reduce indoor malaria transmission in areas with high bed net coverage. Parasit Vectors. 2013;6:57. 
32. Bøgh C, Clarke SE, Walraven GEL, Lindsay SW. Zooprophylaxis, artefact or reality? A paired-cohort study of the effect of passive zooprophylaxis on malaria in The Gambia. Trans R Soc Trop Med Hyg. 2002;96:593-6.

33. Saul A. Zooprophylaxis or zoopotentiation: the outcome of introducing animals on vector transmission is highly dependent on the mosquito mortality while searching. Malar J. 2003;2:32.

34. Donnelly B, Berrang-Ford L, Labbé J, Twesigomwe S, Lwasa S, Namanya $\mathrm{DB}$, et al. Plasmodium falciparum malaria parasitaemia among indigenous Batwa and non-indigenous communities of Kanungu district, Uganda. Malar J. 2016;15:254

35. Ridl FC, Bass C, Torrez M, Govender D, Ramdeen V, Yellot L, et al. A preintervention study of malaria vector abundance in Rio Muni, Equatorial Guinea: their role in malaria transmission and the incidence of insecticide resistance alleles. Malar J. 2008;7:194.

36. Lefevre T, Gouagna LC, Dabire KR, Elguero E, Fontenille D, Renaud F, et al. Beyond nature and nurture: phenotypic plasticity in blood-feeding behavior of Anopheles gambiae s.S. when humans are not readily accessible. Am J Trop Med Hyg. 2009;81:1023-9.

37. Njoroge MM, Tirados I, Lindsay SW, Vale GA, Torr SJ, Fillinger U. Exploring the potential of using cattle for malaria vector surveillance and control: a pilot study in western Kenya. Parasit Vectors. 2017;10:18.
38. Reddy MR, Overgaard HJ, Abaga S, Reddy VP, Caccone A, Kiszewski AE, et al. Outdoor host seeking behaviour of Anopheles gambiae mosquitoes following initiation of malaria vector control on Bioko Island, Equatorial Guinea. Malar J. 2011;10:184.

39. Amoran OE. Impact of health education intervention on malaria prevention practices among nursing mothers in rural communities in Nigeria. Niger Med J. 2013;54:115-22.

40. Unicef. Equatorial Guinea Country programme document 2013-2017. 2013. http://www.unicef.org/about/execboard/files/2012-PL37 Equat orial_Guinea_CPD-final_approved-English.pdf. Accessed 18 June 2016.

41. Romay-Barja M, Ncogo P, Nseng G, Santana-Morales MA, Herrador Z, Berzosa P, et al. Caregivers' malaria knowledge, beliefs and attitudes, and related factors in the Bata District, Equatorial Guinea. PLoS ONE. 2016:11:e0168668.

42. World Bank. The world bank Equatorial Guinea Overview. 2017. http:// www.worldbank.org/en/country/equatorialguinea/overview. Accessed 10 Oct 2017.
Ready to submit your research? Choose BMC and benefit from:

- fast, convenient online submission

- thorough peer review by experienced researchers in your field

- rapid publication on acceptance

- support for research data, including large and complex data types

- gold Open Access which fosters wider collaboration and increased citations

- maximum visibility for your research: over $100 \mathrm{M}$ website views per year

At BMC, research is always in progress.

Learn more biomedcentral.com/submissions 